\title{
Crónica
}

\section{Elección de Presidente y Directorio de la SOCHOG: 2012-2013}

En una ceremonia encabezada por el actual presidente de la Sociedad Chilena de Obstetricia y Ginecología, Dr. Luis Martínez, el martes 27 de diciembre se realizó la elección de Presidente y Directorio de la SOCHOG para el período 2012-2013. El presidente electo fue el Dr. Hernán Muñoz, quien actualmente se desempeña como vice-presidente de esta entidad científica, y que asumirá el cargo a partir de abril de 2012. De acuerdo a los estatutos de la Sociedad Chilena de Obstetricia y Ginecología, el Comité de Búsqueda de esta entidad se reunió en octubre para proponer el listado de postulantes para ejercer los diferentes cargos del directorio para el periodo 2012-2013.

La propuesta de postulantes fue entregada durante una asamblea realizada en el Aula Magna de
Clínica Alemana de Santiago, la cual fue aceptada por todos los miembros presentes en la ocasión.

De esta manera, fueron elegidos por aclamación los siguientes médicos con sus respectivos cargos:

Presidente: Dr. Hernán Muñoz

Vice-presidente: Dr. Mauricio Cuello

Tesorero: Dr. Álvaro Insunza

Secretario general: Dr. Omar Nazzal

Secretarios de Actas: Drs. Carlos Schnapp y José Antonio Arraztoa

Directores: Drs. Manuel Parra, Ricardo Pommer y Susana Aguilera

Santiago, 27 de diciembre de 2011. 